\title{
EFFECTS OF THE SEAT CUSHION OSCILLATORY PARAMETERS ON VIBRATION EXPOSURE AND DYNAMIC SEAT COMFORT IN THE BUS
}

\author{
Dragan Sekulic ${ }^{1^{*}}$ Ivan Ivkovic ${ }^{1}$ Dušan Mladenovic ${ }^{1}$ \\ ${ }^{1}$ University of Belgrade, Faculty of Transport and Traffic Engineering, Belgrade, Serbia
}

The paper analyzed the influence of the passenger seat's cushion oscillatory parameters (stiffness/damping) on ride comfort and dynamic seat comfort. The analysis was done using a linear in-line oscillatory seat-human model with 4 degrees of freedom (DOF) defined in Matlab/Simulink. For the oscillatory excitations of the in-line model, the vertical accelerations of the bus floor under the users' seats were used. Bus floor accelerations were obtained by simulation using validated spatial oscillatory intercity bus model with 65 DOF defined in the ADAMS/View software. The ride comfort was assessed by the criteria of ISO 2631/1997 standard. The seat effective amplitude transmissibility (SEATrms) parameter was considered for analyzing the dynamic seat comfort. It was found that passengers in the rear part of the bus had a lower level of ride comfort than the passengers in the front part of the bus. The intensities of the bus floor vertical accelerations for the rear part were mainly concentrated in the frequency range of 5-10 $\mathrm{Hz}$. Passengers at the rear had lower SEATrms values than those at the front. The SEATrms values increased noticeably with the increase in the cushion stiffness, but those values were below $100 \%$ for all considered users. Increase in the cushion damping slightly decreased SEATrms values.

Key words: Flexible shells, Orthotropy, Oscillations, Mixed finite element method, Galerkin method

\section{INTRODUCTION}

Bus users are exposed to the harmful effect of whole body vibration (WBV) bus ride. The basic oscillatory bus excitation is road roughness. Vibrations are transferred from the road to the bus user's body via the tires, the bus suspension system and the seats. Unlike the bus driver's seat, the passengers' seats are not equipped with suspension system and are rigidly suspended from the bus platform. Vibration damping at passengers' seats is done by elastic cushions. Seat cushion stiffness and damping characteristics influence vibrations transmission from the bus floor to users' bodies, and have an effect on the ride comfort.

The vehicle seat comfort can be divided into static comfort and dynamic comfort. Static seat comfort represents the comfort of the seat when the vehicle is stationary, and with no influence of disturbing forces and vibrations. Dynamic seat comfort refers to the seat overall comfort and includes the vibration effects on the users. The seat that is comfortable for users in static conditions can be uncomfortable in dynamic conditions when the vehicle is moving [05]. Seat dynamic comfort is associated with vibrations transmission from the vehicle floor to the user's body. The transfer of vibrations depends on the intensity and frequency of the excitation [13] , the direction of the excitation [13] , the sitting posture (erected/normal/ slouched) [11] and the oscillatory characteristics of the seat. Dynamic seat comfort also depends on person's subjective feeling of the vibration effect. Vibrations of low frequencies (up to $12 \mathrm{~Hz}$ ) affect the entire human body.
Human body is the most sensitive to vertical vibrations in the frequency range $4-8 \mathrm{~Hz}$, and on the horizontal vibrations in the range 1-2 Hz. Vibrations of higher frequencies (above $12 \mathrm{~Hz}$ ) have a local effect and affect particular part of the human body (e.g. arms, shoulders, head, legs, etc.).

Bus passengers' exposure to vibration depends on the position of their seats in the bus [16]. Experimental and simulation studies have shown that passengers in the front and rear part of the bus suffer high acceleration intensities [04] and [16]. In this paper, the influence of the seat cushion oscillatory parameters on the users' ride comfort and dynamic seat comfort were investigated. Two users at the front of the bus, whose seats are positioned on the front overhang and above the front axle, were taken into account. Two passengers in the rear part of the bus with the seats positioned in the last row at the rear overhang and above the rear axle were also analyzed. For the purpose of the analysis, the validated spatial oscillatory model of the intercity bus with 65 DOF built in the ADAMS/ View software was used. The model was excited with the real road roughness - bad asphalt-concrete pavement registered at two tracks at speed of $64 \mathrm{~km} / \mathrm{h}$. Bus floor acceleration signals under the users' seat were obtained using the model. Vertical acceleration signals were used as the excitation for the in-line 4 DOF human-seat model. In-line model was defined in the Matlab/Simulink. Root-mean-square ( $r m s$ ) values of the weighted vertical acceleration are analyzed when assessing ride comfort. 
For the analysis of dynamic seat comfort, the SEATrms parameter is analyzed.

\section{SEAT-HUMAN OSCILLATORY MODEL}

Under the influence of vibration, the motion of human body depends on excitation frequencies. It has been found that the human body behaves as rigid at low oscillation frequencies, below $2 \mathrm{~Hz}$ [11]. At higher oscillation frequencies, the upper parts of the body (shoulders, arms and head) are loosely coupled and relatively move. At higher frequencies human body behaves as a complex mechanical oscillatory system [07]. Considerable number of biodynamic human body models with different number of masses and DOF exist in literature (2 DOF model [17]; 2 DOF model [02]; 2 DOF [06]; 4 DOF model proposed by ISO CD 5982 [08]; 4 DOF model [03]; 5 DOF model [12]). The parameters of these models were mainly determined by experimental measurement of the biodynamic responses of a seated human body when affected with vibration. Biodynamic responses are the quantities determined by three different biodynamic functions - driving point mechanical impedance (DPMI), apparent mass (APMS) and seat-to-head transmissibility (STHT) [10].

In this paper, the analysis was performed using a linear in-line seat-human model (Figure 1). When defining seat-human model, a linear biodynamic human body model with 4 DOF proposed by Boileau and Rakheja [03] was used. In the seat-human model, the connection between the human body and the seat is represented by an elastic-damping element with an equivalent coefficient of stiffness $\mathbf{c 4}^{\prime}$ ' and an equivalent coefficient of damping ' b4'. Equivalent coefficients are determined based on the serial connection between seat cushion and human buttocks oscillatory parameters (Eqs. (1-2)). Parameter values for the linear seat-human oscillatory model are provided in Table 1.

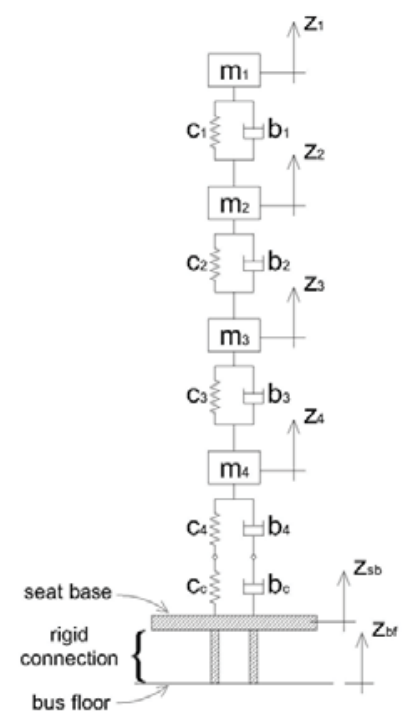

Figure 1: Oscillatory seat-human model

$$
c_{4}^{\prime}=\frac{c_{4} \cdot c_{c}}{c_{4}+c_{c}} \quad \text { 1) } \quad b_{4}^{\prime}=\frac{b_{4} \cdot b_{c}}{b_{4}+b_{c}}
$$

It should be noted that the seat cushion has non-linear characteristics of stiffness and damping. They depend on the human body mass, the amplitude and frequency of the excitation [19], as well as the characteristics of the cushion material. The seat cushion under load over time changes elastic characteristic, i.e. becomes stiffer and loses the ability to isolate vibration [01]. The paper analyzes the influence of different seat cushion stiffness/ damping coefficient values on the vibration transfer from the bus floor to the users' bodies. Five different values of the stiffness/damping coefficients from the range of \pm $50 \%$ of their nominal values are considered ( $\mathrm{cc}=10000$, $15000,20000,25000,30000 \mathrm{~N} / \mathrm{m}$; bc=110, 165, 220, $275,330 \mathrm{Ns} / \mathrm{m})$.

Differential equations of motion for oscillatory model are given by Eqs. (3-6):

$$
\begin{aligned}
& m_{1} \ddot{z}_{1}+b_{1} \dot{z}_{1}+c_{1} z_{1}-b_{1} \dot{z}_{2}-c_{1} z_{2}=0 \\
& m_{2} \ddot{z}_{2}+\left(b_{1}+b_{2}\right) \dot{z}_{2}+\left(c_{1}+c_{2}\right) z_{2}- \\
& -b_{1} \dot{z}_{1}-c_{1} z_{1}-b_{2} \dot{z}_{3}-c_{2} z_{3}=0 \\
& m_{3} \ddot{z}_{3}+\left(b_{2}+b_{3}\right) \dot{z}_{3}+\left(c_{2}+c_{3}\right) z_{3}- \\
& -b_{2} \dot{z}_{2}-c_{2} z_{2}-b_{3} \dot{z}_{4}-c_{3} z_{4}=0 \\
& m_{4} \ddot{z}_{4}+\left(b_{3}+b_{4}{ }^{\prime}\right) \dot{z}_{4}+\left(c_{3}+c_{4}{ }^{\prime}\right) z_{4}- \\
& -b_{3} \dot{z}_{3}-c_{3} z_{3}=b_{4}{ }^{\prime} \dot{z}_{s b}+c_{4}{ }^{\prime} z_{s b}
\end{aligned}
$$

On the basis of the differential equations, the oscillatory seat-human model was formed in the Matlab/Simulink. Figure 2 displays top level Simulink diagram. Since passenger's seat is not equipped with a suspension system, the signal of bus floor vertical acceleration is taken as model excitation input. Vertical acceleration of the mass $\mathrm{m} 4$ was analyzed as model response since it is an indicator of the user' WBV exposure.

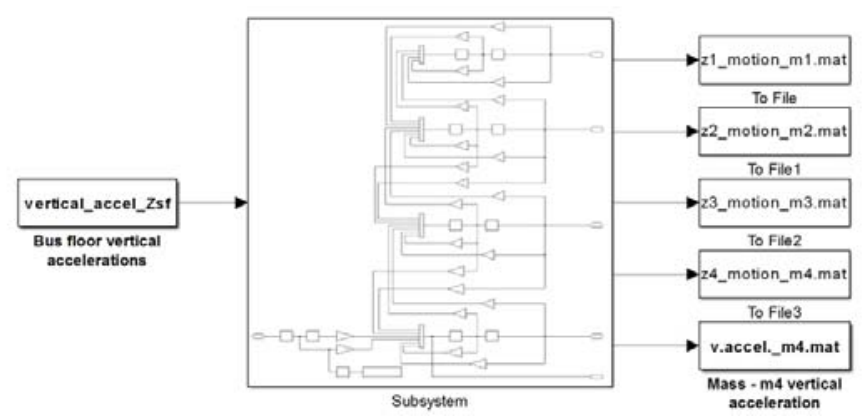

Figure 2: Top level Simulink diagram 
Table 1: Parameters for seat-human model

\begin{tabular}{|l|c|l|c|}
\hline Parameters of the model & Values & Parameters of the model & Values \\
\hline $\mathrm{m}_{1}$ - head and neck & $5.31[\mathrm{~kg}]$ & $\mathrm{b}_{\mathrm{c}}$ - cushion damping & $220[\mathrm{Ns} / \mathrm{m}]$ \\
\hline $\mathrm{m}_{2}$ - chest and upper torso & $28.49[\mathrm{~kg}]$ & $\mathbf{b}_{4}{ }^{\prime}$ - equivalent damping & $198.81[\mathrm{Ns} / \mathrm{m}]$ \\
\hline $\mathrm{m}_{3}$ - lower torso & $8.62[\mathrm{~kg}]$ & $\mathrm{c}_{1}$ - cervical spine stiffness & $310000[\mathrm{~N} / \mathrm{m}]$ \\
\hline $\mathrm{m}_{4}$ - thighs and pelvis & $12.78[\mathrm{~kg}]$ & $\mathrm{c}_{2}$ - thoracic spine stiffness & $183000[\mathrm{~N} / \mathrm{m}]$ \\
\hline $\mathrm{b}_{1}$ - cervical spine damping & $400[\mathrm{Ns} / \mathrm{m}]$ & $\mathrm{c}_{3}$ - lumbar spine stiffness & $162800[\mathrm{~N} / \mathrm{m}]$ \\
\hline $\mathrm{b}_{2}$ - thoracic spine damping & $4750[\mathrm{Ns} / \mathrm{m}]$ & $\mathrm{c}_{4}$ - buttocks stiffness & $90000[\mathrm{~N} / \mathrm{m}]$ \\
\hline $\mathrm{b}_{3}$ - lumbar spine damping & $4585[\mathrm{Ns} / \mathrm{m}]$ & $\mathrm{c}_{\mathrm{c}}$ - cushion stiffness & $20000[\mathrm{~N} / \mathrm{m}]$ \\
\hline $\mathrm{b}_{4}$ - buttocks damping & $2064[\mathrm{Ns} / \mathrm{m}]$ & $\mathrm{c}_{4}{ }^{\prime}$ - equivalent stiffness & $16364[\mathrm{~N} / \mathrm{m}]$ \\
\hline
\end{tabular}

Figure 3 shows acceleration transmissibility function of the seat. The resonant frequency of the seat is approximately $2.5 \mathrm{~Hz}$. The values of the function are lower than one for frequencies above $3.5 \mathrm{~Hz}$. The seat isolates vibrations at frequencies above $3.5 \mathrm{~Hz}$.

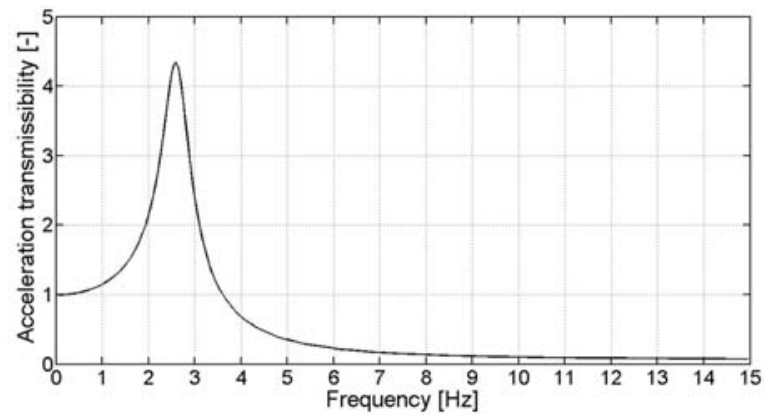

Figure 3: Acceleration transmissibility function for user's seat

\section{BUS MODEL AND THE SEAT-HUMAN MODEL EXCITATIONS}

In the spatial oscillatory intercity bus model (Figure 6), real unevenness of the asphalt-concrete pavement in poor condition was introduced (Figure 4). A measuring vehicle registered roughness irregularities along two tracks (left and right) on a $161 \mathrm{~m}$ long section at a speed of $64 \mathrm{~km} / \mathrm{h}$. Roughness irregularities were taken from the PROFILES database of RoadRuf software [14].

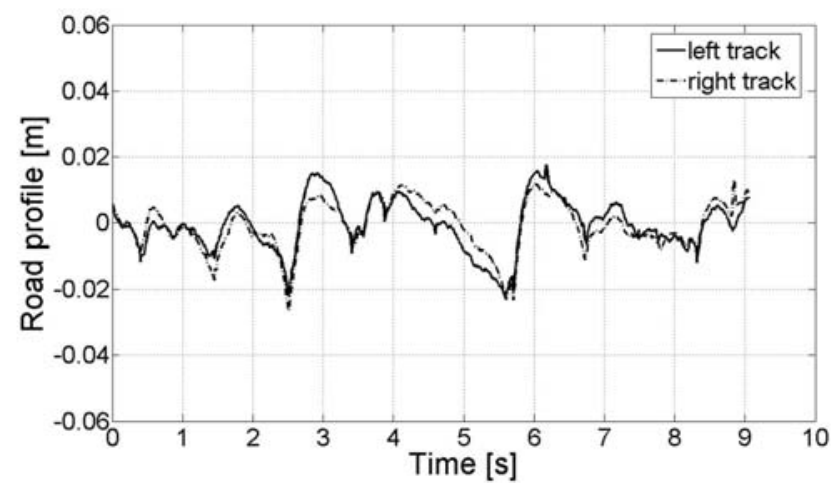

Figure 4: Road roughness on the left and right tracks

The validation of the bus model was done by comparing the bus floor vertical acceleration signals determined by measurement and simulation. Vertical acceleration signals were taken on floor below the passenger's seat positioned above the rear axle and below driver's seat. The model validation is shown in more detail in [15]. It should be pointed out that the excitation signal presented in Figure 4 was used for the purpose of simulation.

Figure 5 shows the intercity IK 301 bus with the basic geometric parameters (Figure 5a) and the seat layout on the front, middle and rear part of the bus (Figure 5b). Figure 6 shows spatial bus model built in the ADAMS/View software. Figure 6 also displays the position of markers on the bus floor below the users' seats for registering vertical accelerations.

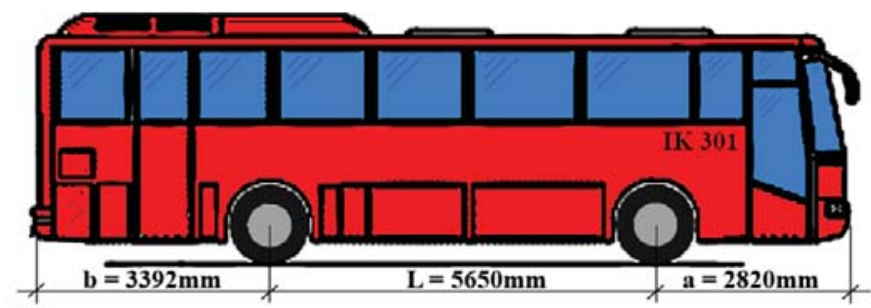

(a)

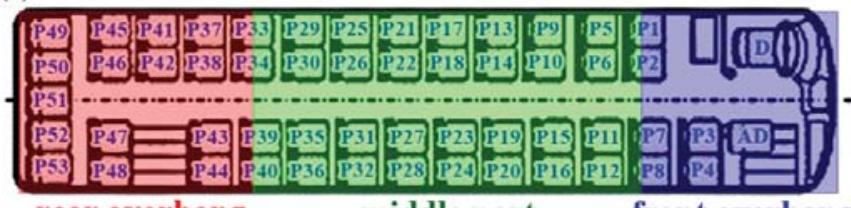

(b)

middle part

front overhang

Figure 5: Intercity bus IK 301

a) basic geometry parameters, b) seats layout

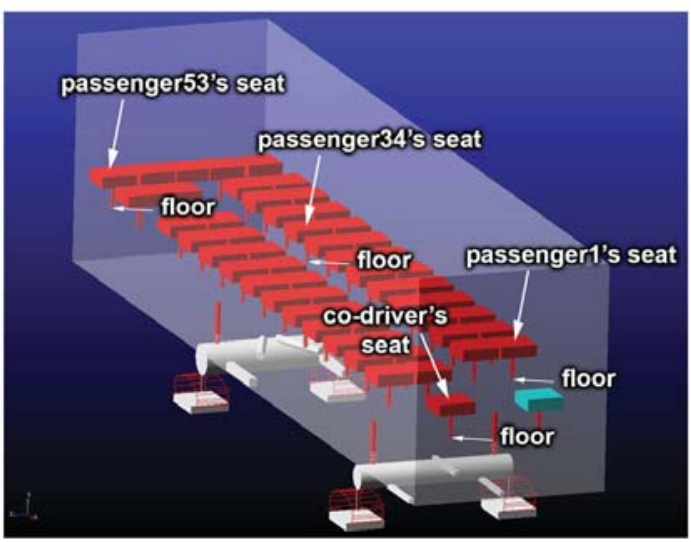

Figure 6: Spatial bus oscillatory model in ADAMS/View 
As an example, Figure 7 shows the bus floor accelerations below the passenger53's seat. It is noticed that the vertical acceleration of the floor has the greatest intensity. Figure 8 comparatively displays the bus vertical accelerations below users' seats at the front and rear part of the bus. It is noted that the bus floor vertical acceleration below the passenger53's seat has the greatest intensity and pronounced peaks. Accelerations presented in Figure 8 were introduced as input signals in the oscillatory human-seat model (Figure 2).

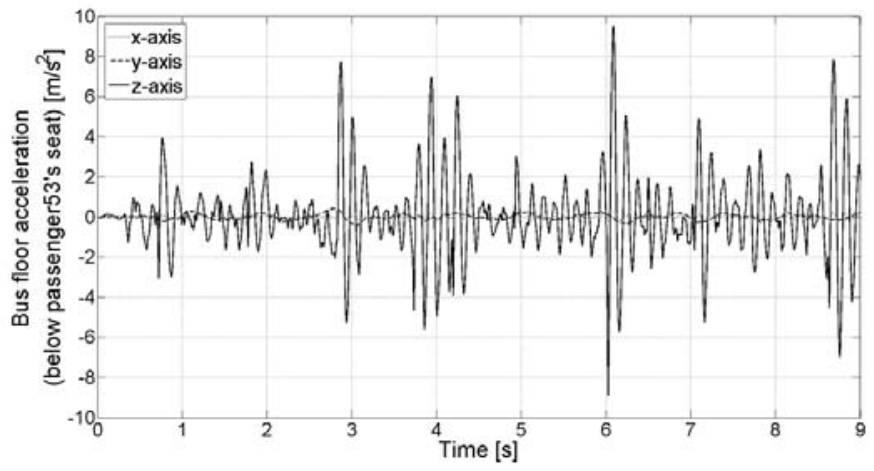

Figure 7: Bus floor acceleartions below the passenger53's seat

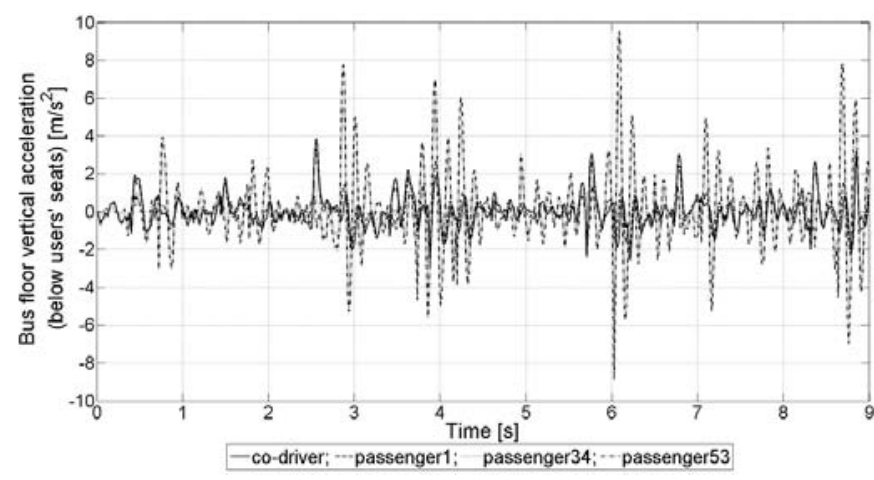

Figure 8: Bus floor vertical acceleartions below bus users' seats

Figure 9a shows the power spectral density (PSD) of bus floor vertical accelerations. It is noted that the acceleration intensities for the rear part of the bus are concentrated in the frequency range $5-10 \mathrm{~Hz}$. These accelerations are markedly higher values than those for the front part of the bus. At lower frequencies (around $1 \mathrm{~Hz}$ ), PSD of the bus floor vertical accelerations for the front part are higher values compared to accelerations for the rear part.

\section{PARAMETERS FOR WBV EXPOSURE ANALYSIS}

Standard ISO 2631/1997 recommends two parameters for estimating WBV effects, total rms value of weighted acceleration and Vibration Dose Value (VDV). The total rms value is the basic parameter and includes three translational accelerations along $x, y$ and $z$ axes acting on human body through the seat. In this paper, only vertical acceleration is taken into account because of the highest intensities.

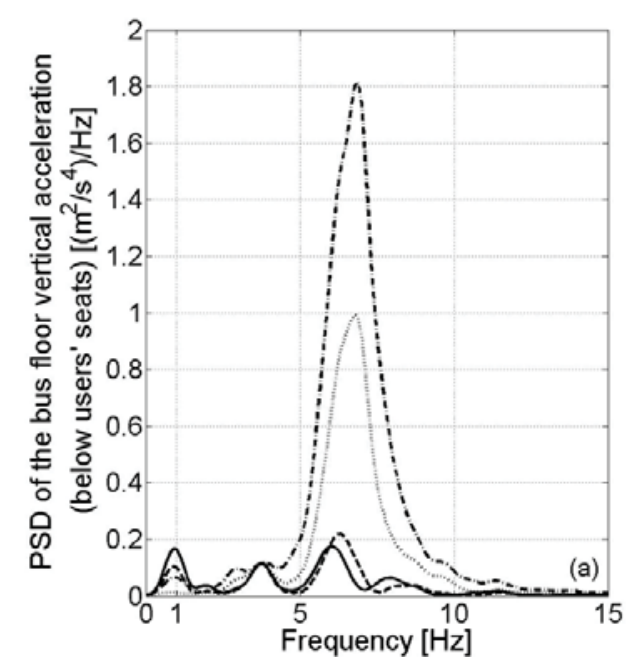

a)

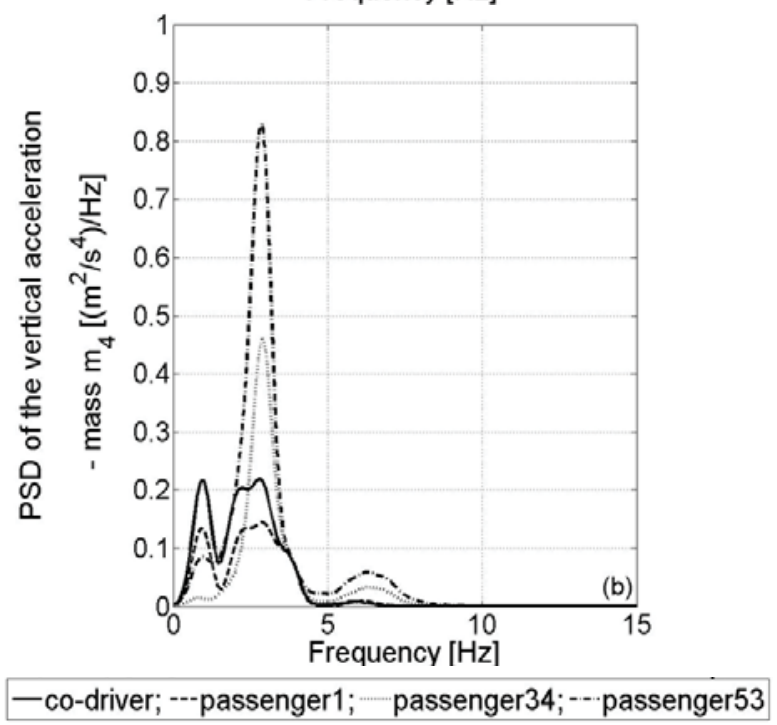

Figure 9: PSD of the vertical acceleration for a) bus floor, b) mass $m 4$

Rms value of the weighted vertical acceleration is calculated by Eq. 7. ISO 2631/1997 standard specifies Wk filter for vertical acceleration weighting [09].

$$
\ddot{z}_{r m s, w}=\left(\frac{1}{T} \int_{0}^{T} \ddot{z}_{w}{ }^{2}(t) d t\right)^{1 / 2}
$$

where $\ddot{z} w(t)$ is the weighted vertical acceleration in function of time; $T$ is the duration of the simulation.

Comfort criteria proposed by ISO 2631/1997 are used to assess the vibration effects, Table 2.

Table 2: Comfort assessment

\begin{tabular}{|c|c|}
\hline Vibration intensity & Comfort assessment \\
\hline$<0.315\left[\mathrm{~m} / \mathrm{s}^{2}\right]$ & not uncomfortable \\
\hline $0.315-0.63\left[\mathrm{~m} / \mathrm{s}^{2}\right]$ & a little uncomfortable \\
\hline $0.5-1.0\left[\mathrm{~m} / \mathrm{s}^{2}\right]$ & fairly uncomfortable \\
\hline $0.8-1.6\left[\mathrm{~m} / \mathrm{s}^{2}\right]$ & uncomfortable \\
\hline $1.25-2.5\left[\mathrm{~m} / \mathrm{s}^{2}\right]$ & very uncomfortable \\
\hline$>2.0\left[\mathrm{~m} / \mathrm{s}^{2}\right]$ & extremely uncomfortable \\
\hline
\end{tabular}


According to [09], WBV exposure assessment using $r m s$ value of the weighted acceleration is limited and depends on Crest Factor (CF) value (Eq. 8). The high CF values indicate that the acceleration signal contains shock vibrations.

$$
C F=\frac{\left|\ddot{z}_{\max (w, \text { seat })}\right|}{\ddot{z}_{\text {rms }(w, \text { seat })}}=\frac{\max \left|\ddot{z}_{w, \text { seat }}(t)\right|}{\left(\frac{1}{T} \int_{0}^{T} \ddot{z}^{2} w, \text { seat }(t) d t\right)^{1 / 2}}
$$

where $\max \mid \ddot{z} w$, seat $(t) \mid$ is the maximum absolute value of the weighted vertical acceleration at the seat.

When CF value is greater than 9, the ISO 2631/1997 standard specifies additional parameter VDV for the assessment of the WBV effect (Eq. 9). This parameter is more sensitive to the acceleration peaks compared to the basic parameter and considers the fourth power of the weighted vertical acceleration.

$$
V D V=\left(\frac{1}{T} \int_{0}^{T} \ddot{z}_{w}^{4}(t) d t\right)^{1 / 4}
$$

\section{PARAMETER SEAT}

Dynamic seat comfort assessment can be done by parameter SEAT. This is an objective measure that is often used to compare isolation characteristic of the seats equipped with different suspension systems when excitated with the same input signals [01]. Although all passenger seats have the same seat cushion oscillatory parameters, the bus floor excitations are not the same. In this paper, the parameter SEAT is used to compare the isolation characteristics of the users' seats in the function of their position on the bus platform.

$$
S E A T_{r m s}[\%]=\frac{\ddot{z}_{\text {rms }(w, \text { seat })}}{\ddot{z}_{r m s(w, \text { floor })}} \cdot 100=\frac{\left(\frac{1}{T} \int_{0}^{T} \ddot{z}^{2}{ }_{w, \text { seat }}(t) d t\right)^{1 / 2}}{\left(\frac{1}{T} \int_{0}^{T} \ddot{z}^{2}{ }_{w, \text { floor }}(t) d t\right)^{1 / 2}} \cdot 100
$$

where z̈rms(w,seat) and z̈rms(w,floor) are rms values of the weighted vertical accelerations on the seat and the bus floor below the seat respectively.

Standard ISO 2631/1997 recommends VDV for assessing the parameter SEAT when acceleration signal contains pronounced peaks, Eq. 11.

$$
S E A T_{V D V}[\%]=\frac{V D V_{\text {seat }}}{V D V_{\text {floor }}} \cdot 100=\frac{\left(\frac{1}{T} \int_{0}^{T} \ddot{z}^{4}{ }^{w, \text { seat }}(t) d t\right)^{1 / 4}}{\left(\frac{1}{T} \int_{0}^{T} \ddot{z}^{4}{ }_{w, \text { floor }}(t) d t\right)^{1 / 4}} \cdot 100
$$

where VDVseat and VDVfloor are vibration dose values for seat and bus floor below the seat respectively.
SEAT value greater than $100 \%$ indicates that the seat amplifies bus floor vibrations; if the SEAT value is equal to $100 \%$, the seat do not isolate floor vibration, and there is no improvement in ride comfort; the seat attenuates some vibration if SEAT value is less than $100 \%$.

\section{RESULTS ANALYSIS AND DISCUSSION}

The paper analyzes the WBV exposure of bus users and dynamic comfort of their seats. Exposure to WBV was determined by the weighted vertical acceleration of the mass $m 4$ and VDV. The SEAT parameter was used to analyze dynamic seat comfort.

Figure 10 shows the vertical acceleration of the user's mass $m 4$. It is noticed that the passengers in the rear of the bus are exposed to higher vertical acceleration intensities. Table 3 gives the rms values of the vertical acceleration for the bus floor below the users' seats and for the users' mass $m 4$. The rms acceleration values on the floor are of higher values, indicating that passenger seats attenuate vertical vibration.

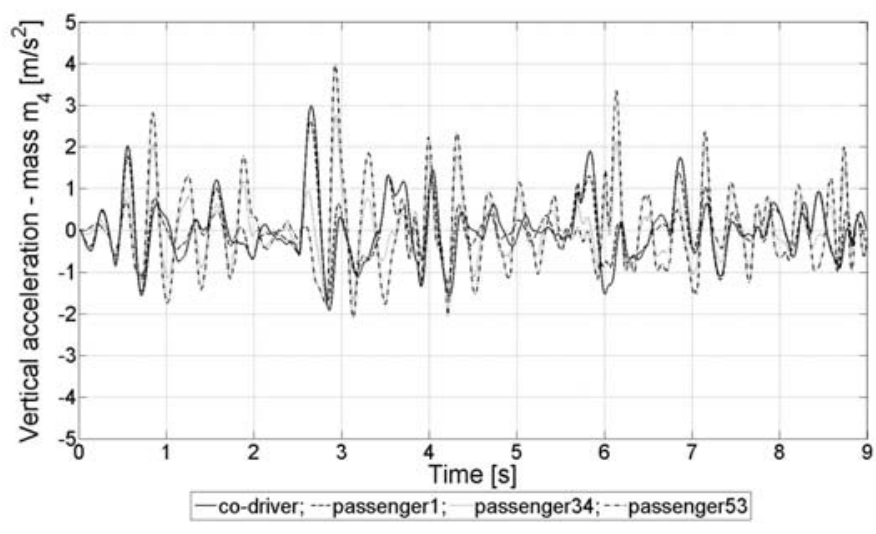

Figure 10: Vertical acceleartions of the mass $m 4$

Figure 9b shows the PSD of the mass $m 4$ vertical accelerations. Accelerations' intensities are concentrated at lower frequencies near the resonance frequency of the seat (about $2.5 \mathrm{~Hz}$ ) and are of lower values compared to the vertical accelerations of the bus floor. Passenger53 has the highest PSD acceleration value, approximately $0.8(\mathrm{~m} 2 / \mathrm{s} 4) / \mathrm{Hz}$.

\section{Bus users' exposure to WBV}

Figure 10a shows the change in $r m s$ values of the weighted vertical acceleration for bus users in the function of the seat cushion stiffness and for the nominal damping value. Passenger53 has the highest rms acceleration values, and apparently the lowest ride comfort. When cushion stiffness increasing, rms acceleration increases considerably for all bus users.

Figure 10b shows the change in rms values of the weighted vertical acceleration in function of the seat cushion damping and for the nominal stiffness value. When cushion damping increasing, rms acceleration gradually decreases for all bus users. Higher damping values provide somewhat better ride comfort. 
Table 3: Rms vertical acceleration values for bus floor and mass m4

\begin{tabular}{|c|c|c|c|c|}
\hline & co-driver & passenger1 & passenger34 & passenger53 \\
\hline Floor rms vertical acceleration $\left[\mathrm{m} / \mathbf{s}^{2}\right]$ & 0.811 & 0.782 & 1.456 & 2.018 \\
\hline Mass $\mathbf{m} 4 \mathrm{rms}$ vertical acceleration $\left[\mathrm{m} / \mathrm{s}^{2}\right]$ & 0.738 & 0.621 & 0.698 & 0.973 \\
\hline
\end{tabular}

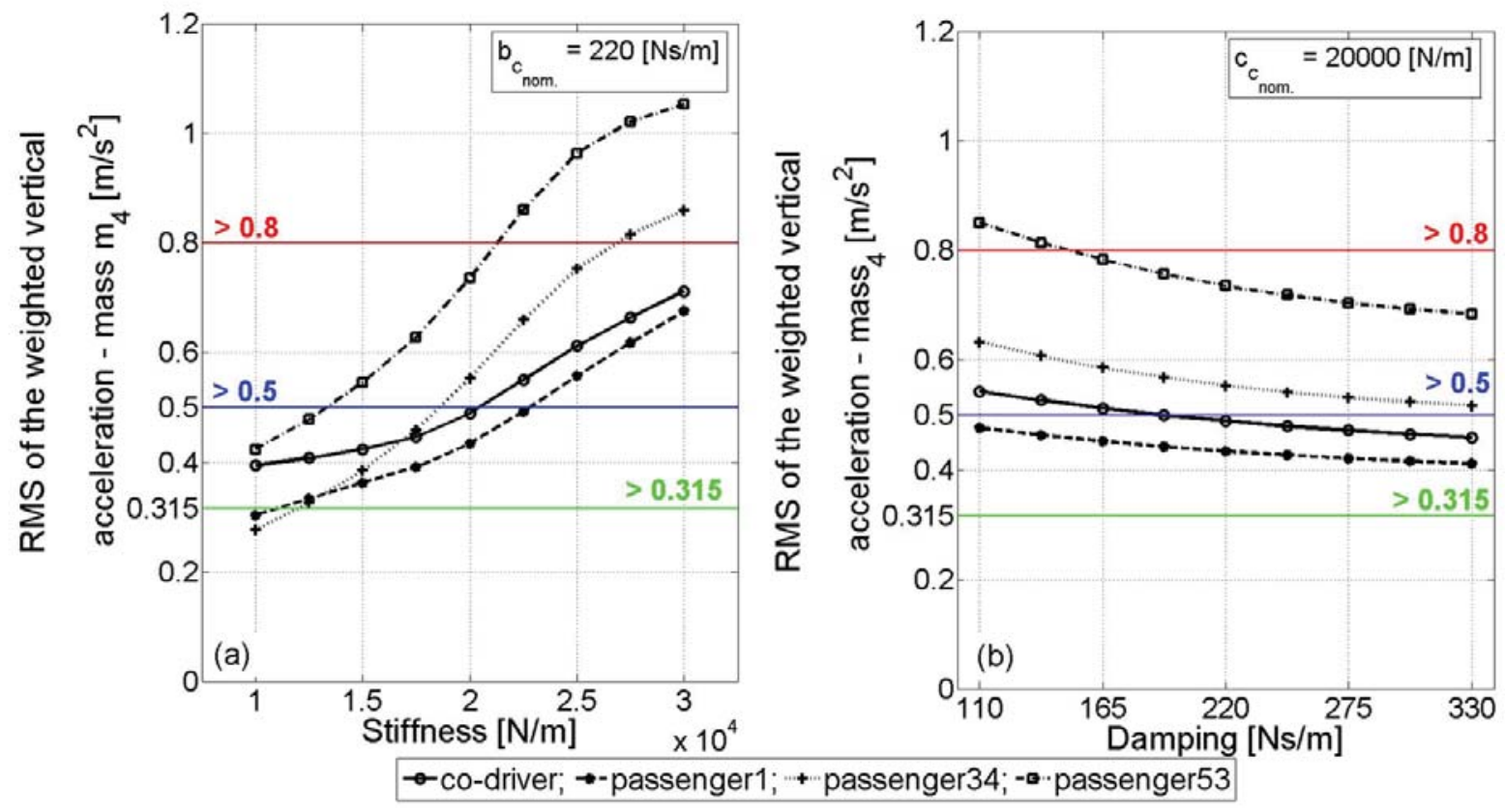

Figure 10: Change of rms value of the weighted vertical acceleration in the function of a) seat cushion stiffness for nominal damping, b) seat cushion damping for nominal stiffness

Table 4 gives the calculated $r m s$ values of the weighted vertical acceleration and VDV parameters for the nominal values of the seat cushion's oscillatory parameters. Table 4 also provides an estimate of the ride comfort according to [09]. Bus users in the front part have better ride comfort than the passengers at the rear bus part. The calculated CF value is approximately the same for all users (approximately equal to 4). In Table 4, calculated VDV values are also given. Higher VDV values for rear passengers indicate lower ride comfort level compared to passengers in the front part of the bus.

As an example, Table 5 provides an estimate of the ride comfort for passenger34 in the function of his seat cushion oscillatory parameters. For nominal damping value, when stiffness increasing, the ride comfort level is reduced from "comfortable" to "uncomfortable". For the nominal stiffness value, the rms acceleration decreases gradually with the increase in damping values. However, ride comfort level for the passenger34 does not change and the estimate is "fairly uncomfortable".

\section{Estimation of the users' seat dynamic comfort}

Table 6 shows SEAT values calculated by two procedures for the nominal values of the seat cushion oscil- latory parameters. Users at the bus front have higher SEAT values than the passengers in the rear of the bus. The values of both SEAT parameters slightly differ for each individual bus user.

Since the calculated CF values are less than 9 (Table 4), the effect of the seat cushion oscillatory parameters on vibration attenuation will be analyzed by SEATrms only.

Figure 11a shows the change of SEATrms in the function of seat cushion stiffness for the nominal damping value. For all stiffness values and for all bus users, the SEATrms values are lower than $100 \%$, indicating that the seats attenuate vertical vibrations. For the maximum cushion stiffness of the $30000 \mathrm{~N} / \mathrm{m}$, SEATrms value for co-driver is approximately equal to $100 \%$ (the seat does not attenuate vertical vibration). SEATrms values are approximately the same for both passengers at the rear of the bus for the entire range of cushion stiffness. SEATrms values are lower for the passengers at the rear compared to those at the front of the bus. Both passengers' seats at the bus rear part attenuate vibrations with the highest acceleration intensities in the frequency range $(5-10 \mathrm{~Hz})$. 
Table 4: Characteristic parameters for ride comfort assessment

\begin{tabular}{|c|c|c|c|c|}
\hline & co-driver & passenger1 & passenger34 & passenger53 \\
\hline $\begin{array}{c}\text { Rms value of the weighted } \\
\left.\text { vertical acceleration [m/s }{ }^{2}\right]\end{array}$ & 0.489 & 0.434 & 0.554 & 0.737 \\
\hline $\begin{array}{c}\text { Comfort assessment } \\
\text { (ISO 2631/1997) }\end{array}$ & $\begin{array}{c}\text { Little } \\
\text { uncomfortable }\end{array}$ & uncomfortable & uncomfortable & uncomfortable \\
\hline CF [-] & 4.047 & 4.229 & 3.921 & 4.089 \\
\hline VDV [m/s $\mathbf{s}^{\mathbf{1 . 7 5}]}$ & 1.234 & 1.086 & 1.392 & 1.892 \\
\hline
\end{tabular}

Table 5: Ride comfort assessment in function of seat cushion oscillatory parameters for passenger 34

\begin{tabular}{|c|c|c|c|c|c|}
\hline \multicolumn{3}{|c|}{$\begin{array}{l}\text { For nominal cushion damping value } \\
\qquad\left(b_{c}=220[\mathrm{Ns} / \mathrm{m}]\right)\end{array}$} & \multicolumn{3}{|c|}{$\begin{array}{l}\text { For nominal cushion stiffness value } \\
\qquad\left(c_{c}=20000[\mathrm{~N} / \mathrm{m}]\right)\end{array}$} \\
\hline $\begin{array}{l}\text { Stiffness } \\
(\mathrm{N} / \mathrm{m})\end{array}$ & $\begin{array}{l}\text { Weighted rms vertical } \\
\text { acceleration }\left(\mathrm{m} / \mathrm{s}^{2}\right)\end{array}$ & $\begin{array}{c}\text { Comfort } \\
\text { assessment } \\
\text { (ISO 2631/1997) }\end{array}$ & $\begin{array}{l}\text { Damping } \\
\text { (Ns/m) }\end{array}$ & $\begin{array}{l}\text { Weighted rms vertical } \\
\text { acceleration }\left(\mathrm{m} / \mathrm{s}^{2}\right)\end{array}$ & $\begin{array}{c}\text { Comfort } \\
\text { assessment } \\
\text { (ISO 2631/1997) }\end{array}$ \\
\hline$-50 \%$ & 0.276 & Comfortable & $-50 \%$ & 0.633 & $\begin{array}{c}\text { Fairly } \\
\text { uncomfortable }\end{array}$ \\
\hline$-25 \%$ & 0.385 & $\begin{array}{c}\text { Little } \\
\text { uncomfortable }\end{array}$ & $-25 \%$ & 0.587 & $\begin{array}{c}\text { Fairly } \\
\text { uncomfortable }\end{array}$ \\
\hline $\begin{array}{l}\text { Nominal } \\
\text { value }\end{array}$ & 0.554 & $\begin{array}{c}\text { Fairly } \\
\text { uncomfortable }\end{array}$ & $\begin{array}{l}\text { Nominal } \\
\text { value }\end{array}$ & 0.554 & $\begin{array}{c}\text { Fairly } \\
\text { uncomfortable }\end{array}$ \\
\hline$+25 \%$ & 0.754 & $\begin{array}{c}\text { Fairly } \\
\text { uncomfortable }\end{array}$ & $+25 \%$ & 0.532 & $\begin{array}{c}\text { Fairly } \\
\text { uncomfortable }\end{array}$ \\
\hline$+50 \%$ & 0.860 & Uncomfortable & $+50 \%$ & 0.517 & $\begin{array}{c}\text { Fairly } \\
\text { uncomfortable }\end{array}$ \\
\hline
\end{tabular}

Table 6: SEAT values for nominal seat cushion oscillatory parameters

\begin{tabular}{|c|c|c|c|c|}
\hline & co-driver & passenger1 & passenger34 & passenger53 \\
\hline SEATrms [\%] & 66.711 & 58.763 & 37.182 & 35.785 \\
\hline SEATVDV [\%] & 63.767 & 57.134 & 34.525 & 33.717 \\
\hline
\end{tabular}




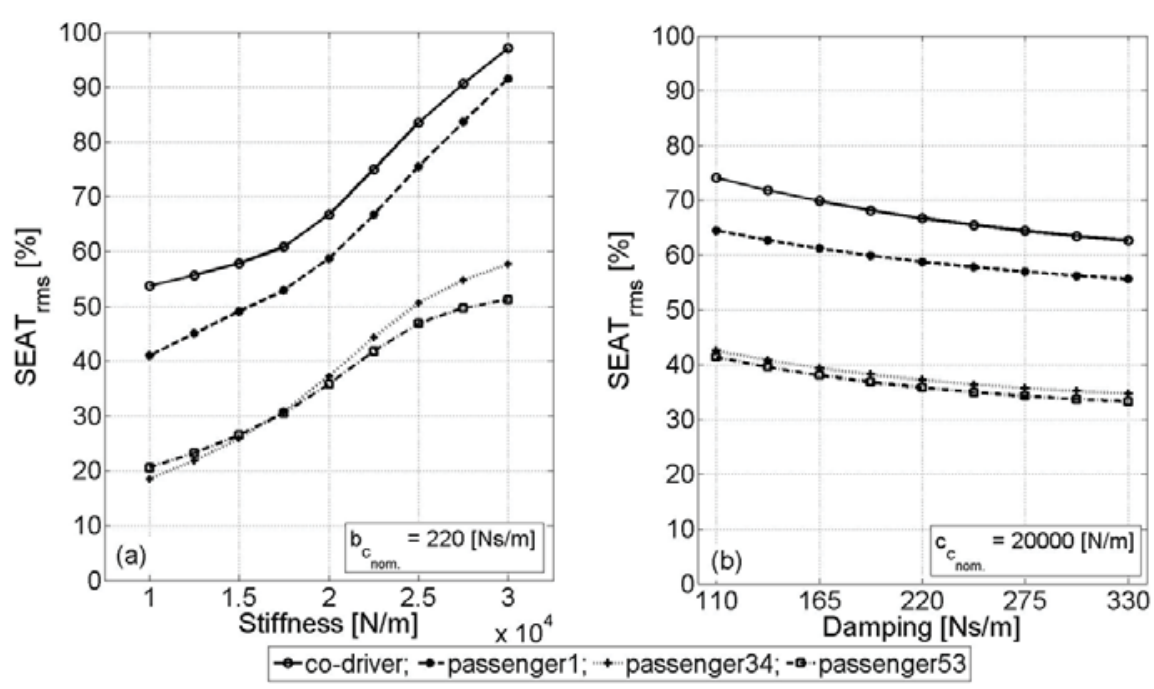

Figure 11: Change of parameter SEATrms in the function of a) seat cushion stiffness for nominal damping value, b) seat cushion damping for nominal stiffness value

(a)

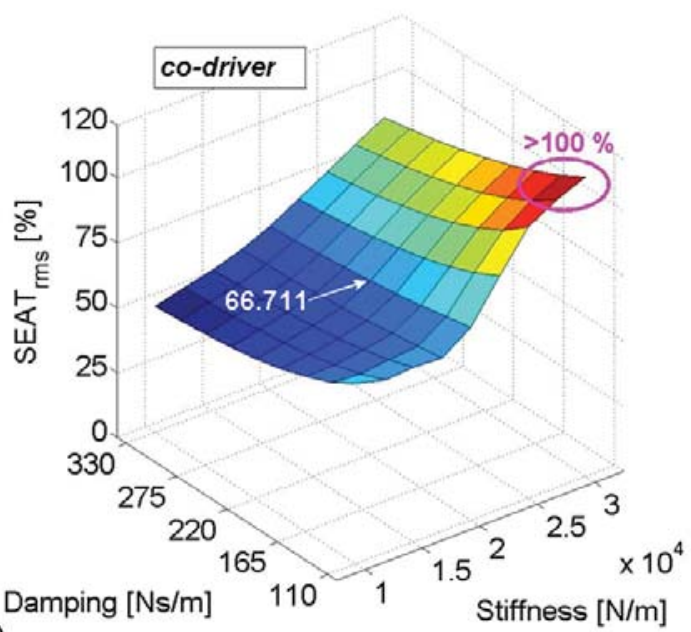

Figure 12: Change of parameter SEATrms in the function of seat cushion oscillatory parameters for a) co-driver, b) passenger53

Figure $11 \mathrm{~b}$ shows the change of SEATrms in the function of the damping cushion for nominal stiffness value. With increase in the damping, SEATrms decrease slightly.

Figure 12(a-b) shows a change in the SEATrms value for co-driver and for passenger53 in the function of seat cushion stiffness and damping. SEATrms values for passenger53 are lower compared to those for co-driver. For low cushion damping and large stiffness, the co-driver's seat amplifies the vertical vibrations that are transmitted from the floor to its body (SEATrms value is greater than $100 \%$ ).

\section{CONCLUSION}

The paper analyzes the intercity bus users' ride comfort and dynamic comfort of their seats in the function of the seat cushion oscillatory parameters for a real road roughness. For the analysis, a linear in-line oscillatory

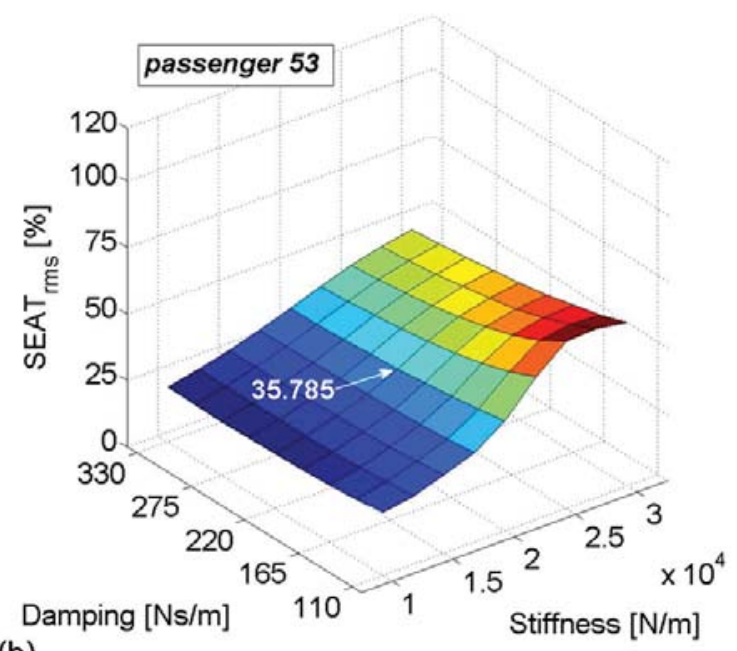

(b) seat-human model with 4 DOF was used. As a model excitation, the vertical accelerations of the bus floor under the users' seats were used. Vertical accelerations of the floor were obtained by simulation using the validated spatial model of the intercity bus built in the ADAMS/View module. Bus model was excited with bad asphalt-concrete road roughness.

The ride comfort rating was performed using the criteria of ISO 2631/1997. Passengers in the rear of the bus are exposed to higher values of vertical acceleration. Passengers at the rear have lower level of ride comfort compared to users in the front of the bus. Rms values of the weighted vertical acceleration increase for all users with the increase in the cushion stiffness. Rms values decrease with the increase in the cushion damping.

Spectral analysis of the bus floor vertical acceleration showed that the acceleration intensities are concentrat- 
ed in the frequency range of $5-10 \mathrm{~Hz}$. The highest floor acceleration is below the passenger seat at the rear bus overhang. Passengers' seats increase acceleration at frequencies that correspond to resonant seat frequency (around $2.5 \mathrm{~Hz}$ ). Seats attenuate the vibrations above $3.5 \mathrm{~Hz}$.

SEATrms are of lower values for the passengers at the rear than for the front bus passengers. Seats attenuate the highest floor vertical acceleration values for both passengers in the rear part of the bus in the frequency range $5-10 \mathrm{~Hz}$. SEATrms values are approximately the same for both passengers at the rear of the bus. For all analyzed cushion stiffness values and for all users, SEATrms values are lower than $100 \%$, indicating that the seats attenuate vertical vibrations. With the increase in the seat cushion damping, SEATrms value decreases slightly.

\section{ACKNOWLEDGEMENTS}

Support for this research was provided by the Ministry of Education, Science and Technological Development of the Republic of Serbia under Grant No. TR36027. This support is gratefully acknowledged.

\section{REFERENCES}

1. Ahmadian, M., Seigler, M.T., Cllapper, D., Sprouse, A. (2002) A Comparative Analysis of Air-inflated and Foam Seat Cushions for Truck Seats, SAE International, pp. 11.

2. Allen, G.R. (1979) A Critical Look at Biodynamic Modeling in Relation to Specifications for Human Tolerance of Vibration and Shock, part 2. In: AGARDCP-253, paper A 25, pp. 519.

3. Boileau, P., Rakheja, S. (1998) Whole-body vertical biodynamic response characteristics of the seated body biodynamic response under vertical vibration. Journal of Sound and Vibration, 215 (4), pp. 841-62.

4. Diligenski, Dj., Demić, M., Šakota, Ž. (2005) Bus passenger vibrational comfort. MVM Monograph, Faculty of Mechanical Engineering, Kragujevac.

5. Ebe, K., Griffin, M.J. (2000) Qualitative models of seat discomfort including static and dynamic factors. Ergonomics, 43 (6), pp. 771-790.

6. Fairley, T.E., Griffin, M.J. (1989) The Apparent Mass of the Seated Hurnan Body: Vertical Vibration. Journal of Biomechanics, 22 (2), pp. 81-94.

7. Griffin, M.J. (1978) The evaluation of vehicle vibration and seats. Applied Ergonomics, 9 (1), pp. 15-21.

8. International Organisation for Standardization Cornmittee Draft CD 5982. (1993) Mechanical Driving Point Impedance and Transmissibility of the Human Body, Document ISOmC 108/SC 4N226. pp. 21.

9. International Organisation for Standardization. (1997) Guide for the evaluation of human exposure to whole body vibration, ISO 2631. pp. 31
10. Mahesh, P.N., Gahininath, J.V.P., Rahul, N.Z.P. (2016) Optimization of nonlinear quarter car suspension-seat-driver model. Journal of Advanced Research, 7 (6), pp. 991-1007.

11. Mansfield, N.J. (2006) Literature Review On Low Frequency Vibration Comfort. Loughborough University, Loughborough, U.K., pp. 104.

12. Mertens, H. (1978) Nonlinear Behavior of Sitting Humans Under Increasing Gravity. Aviation, Space and Environmental Medicine, 49 (1), pp. 287-298.

13. Nahvi, H., Fouladi, M.H., Nor, M.J.M. (2009) Evaluation of whole-body vibration and ride comfort in a passenger car. International Journal of Acoustics and Vibration, 14 (3), pp. 143-149.

14. RoadRuf Software. (1997) Software for analyzing road profiles. The University of Michigan Transportation Research Institute.

15. Sekulić, D. (2013) Investigation of Passengers' Oscillatory Comfort in the Bus with Respect to the Seat Position and Quality (Ph.D. thesis) (in Serbian). University of Belgrade, The Faculty of Transport and Traffic Engineering, Belgrade.

16. Sekulić, D., Dedović, V., Rusov, S., Obradović, A., Salinić, S. (2016) Definition and determination of the bus oscillatory comfort zones. International Journal of Industrial Ergonomics, 53, pp. 328-339.

17. Suggs, C.W., Stikeleather, L.F., Harrison, J.Y., Young, R.E. (1970) Application of a Dynamic Simulator in Seat Testing. Transaction ASAE, 13 (3), pp. 378-381.

18. Tchermychouk, V. (1999) Objective assessment of static and dynamic seats under vehicular vibration. Master Thesis, Concordia University, Montreal, Quebec, Canada, pp. 180.

Paper submitted: 20.07.2017.

Paper accepted: 21.09.2017.

This is an open access article distributed under the CC BY-NC-ND 4.0 terms and conditions. 